\title{
Universidade em tempo de mudança
}

\section{University in times of change}

\author{
Eleonora Milano Falcão Vieira' \\ Hans Michael van Bellen² \\ Francisco Antonio Pereira Fialho ${ }^{3}$
}

\begin{abstract}
Resumo
Este artigo analisa a presença da universidade num momento de profundas mudanças na sociedade. Particularmente, nas duas últimas décadas, as novas tecnologias da informação e do conhecimento, as novas formas de gestão e organização, as novas necessidades de formação de especialistas e profissionais, bem como os novos comportamentos sociais vêm exigindo uma multiplicidade de funções das instituições de ensino superior. Nem sempre, porém, as universidades desenvolvem ritmos de atualização compatíveis com as exigências de uma sociedade em rápida transformação. Há um descompasso entre o avanço da sociedade e a estabilidade acadêmica na maioria das instituições de ensino superior. Enquanto a sociedade atual trabalha e avança por impulsos de curto prazo, a universidade, ao contrário, atua a médio e a longo prazo. A estrutura organizacional e acadêmica dessas instituições é, muitas vezes, dominada por forte aparato burocrático (nas federais, principalmente) e pela busca de resultados (nas particulares). Essa realidade gera disfunções acadêmicas responsáveis pelo atraso das universidades como instituições a se destacarem vanguarda da sociedade. 0 tempo de mudança é o tempo da atualização permanente. É preciso, pois, incorporá-la a cada passo dado nas atividades das universidades.
\end{abstract}

Palavras-chaves: universidade; estrutura organizacional; função acadêmica; mudança.

\begin{abstract}
This article analyses the role played by the university in times of deep changes. Particularly, in the last two decades, the new knowledge and information technologies, the new concepts of management and organization, the latest demands in terms of forming specialists and professionals and new social attitudes has been requiring a large variety of responsibilities of the higher education institutions. However, not always universities develop updating rhythms compatible with the demands of a society under such fast transformation. There is a misencounter between the development of society and the academic stability in the majority of the higher education institutions. Nowadays, society works and advances in a short-term perspective while the university works under a medium/long term prospect. Many times, the academic and organizational structure of the higher education institutions is highly bureaucratic (specially federal universities) while the private institutions are strictly in search of results. Such reality is responsible for academic disfunctions, which result in universities as delayed institutions in a new society. A time of change is a time of constant updating and it is necessary to incorporate it into every step taken on the activities at the university.
\end{abstract}

Key-words: university, organizational structure, academic function, change

\footnotetext{
${ }^{1}$ Doutoranda do Programa de Doutorado em Engenharia e Gestão do Conhecimento da Universidade Federal de Santa Catarina. Professora do Departamento de Ciências Contábeis da Universidade Federal de Santa Catarina. Endereço: Universidade Federal de Santa Catarina - Centro Sócio-Econômico/Departamento de Ciências Contábeis - Campus Trindade, Florianópolis - SC - Brasil - CEP 88040-900. E-mail: emfv0006@yahoo.com.br.

2 Doutor em Engenharia de Produção. Professor do Departamento de Ciências Contábeis da Universidade Federal de Santa Catarina. Endereço: Universidade Federal de Santa Catarina - Centro Sócio-Econômico/Departamento de Ciências Contábeis - Campus Trindade, Florianópolis - SC - Brasil - CEP 88040-900 . Email:hansmichael@cse.ufsc.br.

${ }^{3}$ Doutor em Engenharia de Produção pela Universidade Federal de Santa Catarina. Professor do Programa de Doutorado em Engenharia e Gestão do Conhecimento da Universidade Federal de Santa Catarina. Endereço: Universidade Federal de Santa Catarina - Centro Sócio-Econômico/Departamento de Ciências Contábeis - Campus Trindade, Florianópolis - SC - Brasil - CEP 88040-900. E-mail: fapfialho@gmail.com.
}

Artigo recebido em março de 2006 e aceito para publicação em maio de 2006. 


\section{Introdução}

A discussão sobre o papel e a influência da universidade na sociedade moderna vem de longa data. É inegável que a universidade abriu caminho para o entendimento de outra dimensão do conhecimento e da formação humana. Também é incontestável a importância da universidade no campo da pesquisa, servindo de portal a novos conhecimentos e à queda de barreiras que ao longo do tempo se impuseram à inovação e à mudança. Como instituição pública, a universidade complementa a maior conquista da humanidade: o ensino público, gratuito e de qualidade. A universidade ampliou o horizonte do ensino, estimulando novas formas de pensar, refletir, pesquisar e criar, o que é um inegável mérito das instituições de ensino superior (IES).

O acesso à universidade pública é para todos, embora, haja limitações de vagas espaço. Contudo, ela não deixa de ser democrática, garantindo oportunidade de formação superior a todos os segmentos da sociedade. Contraditoriamente, é seletiva, pois não experimenta uma expansão suficiente para atender a um maior contingente da população. A universidade pública (no caso brasileiro, particularmente) perde em número de vagas para as universidades privadas.

No Brasil, o ensino superior é mais privado do que público. Mesmo assim, são as universidades públicas que apresentam os melhores índices de qualidade de ensino e de geração de pesquisas. Elas são as grandes matrizes do conhecimento na sociedade brasileira.

O tempo da globalização colocou uma nova variável no conjunto de vantagens competitivas entre nações e regiões: o conhecimento. Na verdade, a "ciência e a tecnologia tornaram-se elas próprias globalizadas. Calculouse que o número de cientistas que trabalham no mundo é maior hoje do que antes em toda a história da ciência." (GIDDENS, 2000, p.15).

O significado do que foi afirmado é que o conhecimento é global, que a instituição universitária é global, tanto nas formulações programáticas de graduação como na formação pós-graduada. Pelas universidades de todo o mundo se movimentam jovens, professores e especialistas que exercem as práticas do conhecimento, gerando, por sua vez, novos conhecimentos. Portanto, o conhecimento é tanto uma formação quanto uma prática global. Isso não significa, como bem acentuou Hall (2001, p.78), que "parece improvável que a globalização vá simplesmente destruir as identidades nacionais. É mais provável que ela vá produzir, simultaneamente, novas identificações 'globais' e novas identificações 'locais”.

Em um primeiro momento, há efetivamente um trânsito cultural, técnico e científico no interior das universidades do mundo e, posteriormente, pelos campos de atuação profissional. As influências de origem são recíprocas e criam uma identidade cultural global, sem, contudo, deixar de gerar uma identidade cultural local a partir da visão estratégica do estágio de desenvolvimento.

A sociedade global, já bem delineada no início do presente século, consagra, por meio da tecnologia, o curto prazo, a velocidade e a mudança ilimitada. Não torna a condição humana homogênea pela anulação tecnológica das distâncias temporais/espaciais, mas, ao contrário, "emancipa certos seres humanos das restrições territoriais e torna extraterritoriais certos significados geradores de comunidade." (BAUMAN, 1999, p.25). Isso é muito evidente nas universidades brasileiras, pela influência de pensamentos globais por parte de docentes pósgraduados em universidades do exterior.

Não são incomuns conteúdos baseados em realidades bem diferenciadas, tanto do ponto de vista cultural quanto das visões estratégicas para a atuação de empresas e formulação de políticas públicas. A grande contribuição de uma formação global está na reformulação de estruturas curriculares quase sempre fechadas e singularizadas num saber temático. Estruturas plurais, abertas e compatíveis com visões estratégicas globais e locais, certamente, representarão uma significativa ampliação do papel desempenhado pela universidade local numa inserção global. 


\section{Estrutura organizacional}

Esse é um dos pontos particularmente críticos das universidades federais brasileiras. Nelas, as estruturas são extremamente burocratizadas, pesadas, divisionais, tanto nos trâmites administrativos quanto nos acadêmicos. Santos (2001, p.187) se refere "à rigidez funcional e organizacional, à relativa impermeabilidade às pressões externas; enfim, à aversão à mudança". As universidades federais, como órgão públicos, têm uma compulsão burocrática expansiva.

A multiplicidade de funções acadêmicas da universidade parece ter determinado a multiplicidade de funções burocráticas. Dessa forma, à medida que se expandiram as atividades acadêmicas, também cresceu, no mesmo ritmo e com igual amplitude, a estruturação burocrática.

É natural considerar a necessidade de expansão da atividade meio, porém, não houve um projeto de racionalização, de modernização da gestão, e nem mesmo foi aplicado um plano estratégico de desenvolvimento das atividades universitárias. O crescimento ocorreu pelo desdobramento de órgãos e funções, muito mais do que pela necessidade de atendimento às exigências acadêmicas da sociedade. Ora, essa realidade, como em toda organização, "vai acumulando tensões, contradições e ambivalências que vão, progressivamente, se agravando", segundo Castor (2000, p.129). A dicotomia entre o administrativo e o acadêmico se aprofundou. A atividade meio ganhou impulso, assumiu um poder reivindicatório forte, com acentuada modelagem corporativa. $\mathrm{O}$ mesmo aconteceu com os docentes; que organizados em associações ancoradas em sindicatos de orientação político-ideológica formaram corpos de atuação política dentro das universidades.

A burocracia e a política passaram a desempenhar um papel relevante no âmbito acadêmico, favorecidas pela estrutura organizacional. Por outro lado, a estrutura divisional e burocratizada, progressivamente, tornou a universidade federal muito lenta e pouco eficiente no desempenho de suas atividades. É natural que dessa perspectiva, e não atendida em suas reivindicações básicas e legítimas, a universidade tenha se transformado num foco de conflitos sociais, envolvendo funcionários, técnicos, professores e alunos. Um mundo reivindicatório que se agigantou nos últimos anos, ofuscando os mais graves e urgentes problemas do ensino superior brasileiro. Desses problemas, destaca-se, sem dúvida, a necessidade de uma nova estrutura organizacional. Segundo Vieira e Vieira (2003, p.904)

embora a tendência atual ainda tenha um sentido burocrático multiplicador, mesmo utilizando os recursos da informática, uma nova estrutura organizacional mais simples, flexível e ágil pode ser considerada a partir de novos conceitos organizacionais.

A reestruturação contemplaria novos arranjos de poder e formas de gestão fundamentados na instrumentalidade estratégica.

Para Vieira e Vieira (2003, p. 904) "a reestruturação, contudo, não deve se limitar apenas à organicidade e aos novos métodos de gestão. Precisa ir bem mais além, objetivando produzir efeitos concretos nas atividades fins da universidade". O grande empenho analítico e de soluções a serem propostas volta-se para uma estruturação mais flexível, mais ágil, com o uso intensivo das tecnologias e modernos métodos de gestão.

Os novos modelos operacionais levam à libertação de três grandes patologias da burocracia acadêmica, segundo Vieira e Vieira (2003, p.904):

excesso de normalização, a complexidade burocrática e o corporativismo. Essas patologias das organizações públicas, tão presentes na vida universitária, poderão ceder e tender a desaparecer diante dos recursos das tecnologias virtuais, da flexibilidade orgânica e da descentralização do poder. A reestruturação organizacional estabelecerá os princípios e suportes básicos a iniciativas de mudanças nas estratégias.

A operacionalização de um novo modelo a ser desenvolvido nas instituições federais de ensino superior, de acordo com a realidade de cada uma, será um avanço na modernização estrutural e organizacional dessas universidades. 


\section{Funções e disfunções acadêmicas}

Durante centenas de anos a universidade tem assumido a função de fazer avançar o conhecimento. Entre as tradições acadêmicas perenizadas e os novos tempos, a universidade tem ampliado as fronteiras do ensino, da pesquisa e da extensão, tidas como suas funções básicas. Mesmo nas mais tradicionais instituições de ensino do mundo, em molduras estruturais e organizacionais que pouco se alteraram ao longo dos anos, o ensino se renova e desafia o conhecimento com novas teorias, criando e recriando novos conceitos, ampliando continuamente a sabedoria humana.

Santos (2001, p.189) cita um relatório da Organização para Cooperação e Desenvolvimento Econômico (OCDE) que lista a multiplicidade de funções atribuídas à universidade:

- educação geral pós-secundária;

- investigação;

- fornecimento de mão-de-obra qualificada;

- educação e treinamento altamente especializados;

- fortalecimento da competitividade da economia;

- criação de mecanismo de seleção para empregos de alto nível através do credenciamento;

- estimular mobilidade social aos filhos e filhas das famílias operárias;

- prestação de serviço à comunidade em geral;

- criar paradigmas de aplicação de políticas nacionais (exemplo: igualdade de oportunidades para mulheres e minorias raciais); e

- preparação os que exercerão papéis de liderança social.

É difícil compatibilizar tantas funções atribuídas à universidade com os meios disponíveis para que essas funções sejam exercidas. Na verdade, essa listagem pode ser sintetizada ou, por outro lado, ampliada. Talvez, seja mais uma questão crítica do que de responsabilidade intrínseca à instituição universitária. As funções básicas da universidade, sobre as quais deve se aprofundar o tratamento qualitativo, são, sem dúvida:

- a formação técnica e intelectual (sempre atualizada);

- a investigação visando ampliar conhecimentos; e

- disponibilizar para a sociedade não só mentes de vanguarda ao estágio de desenvolvimento da sociedade, como, por programas de ação direta, e da atuação em áreas nas quais seja maior a carências das comunidades.

No Brasil as universidades públicas respondem por cerca de $90 \%$ da produção científica. Goulart, Vieira e Carvalho (2005, p.57) tratam da institucionalização das universidades como loci da produção científica e tecnológica. Em 1969, foi criado o Fundo Nacional de Desenvolvimento Científico e Tecnológico (FNDCT), e um ano depois, o Plano Básico de Desenvolvimento Científico e Tecnológico (PBDCT) que incentivou e deu impulso a projetos de desenvolvimento da ciência e da tecnologia nas universidades federais, em particular. A Financiadora de Estudos e Projetos (Finep), criada na mesma época, tornou-se o órgão instrumentalizador dos grandes projetos de ciência e tecnologia do país.

Um aspecto importante da ação direta da universidade no desenvolvimento é a articulação da academia no eixo global/local. Este artigo já se referiu à presença global da universidade; Goulart, Vieira e Carvalho (2005, p.69) enfocam os aspectos que envolvem a articulação local; ou seja, a importância da universidade no desenvolvimento local. Para os autores (2005, p.72) "o enraizamento da instituição na sociedade é significativamente marcado por sua história, determinando um papel fundamental dessas organizações no ambiente social, o qual influencia e pelo qual é também influenciada”. Isso coloca a necessidade da instituição universitária se manter 
sempre na vanguarda do conhecimento, o que, na verdade, implica um processo de permanente atualização acadêmica.

Esse processo de atualização terá que ser muito dinâmico para que a universidade, em suas funções básicas, possa acompanhar os setores mais dinâmicos da sociedade. Hawking e Mlodinow (2005, p.139) lembram que "a velocidade do progresso é tão alta que o que você aprende na escola ou na universidade está sempre um pouco ultrapassado". Há, portanto, uma visão estratégica acadêmica que deve considerar a flexibilidade curricular, a profundidade dos conteúdos, a pluralidade e o tempo de duração dos cursos de graduação. A graduação deve oferecer um conhecimento e uma formação básicos de alta qualificação, deixando a complementação dos estudos, em diversas modalidades de especialização, para a pós-graduação.

As disfunções do sistema acadêmico das universidades (particularmente, das federais) ocorreram com mais intensidade nas duas últimas décadas. Vários fatores contribuíram para isso. Alguns de ordem institucional, outros de ordem interna.

Desde os anos 1980, a universidade federal deixou de ser uma real prioridade para investimentos do governo federal. A idéia de despesa passou a predominar, criando um clima propício a cortes e à redução de recursos, tanto para a expansão do número de vagas quanto para a contratação de docentes por concurso público. Uma prática nociva se instalou com a contratação de professores temporários para suprir as vagas que surgiam com as aposentadorias. A redução dos investimentos e o não preenchimento de vagas por concurso - além de ausência de uma clara política de valorização da instituição federal de ensino superior pela atualização de sua estrutura, de seus equipamentos e mudanças curriculares significativas - levaram essas instituições a pelo menos três graves crises, bem assinaladas por Santos (2001, p.190): a crise de hegemonia, a crise de legitimidade e a crise institucional.

A crise de hegemonia é basicamente uma crise de qualidade, quando a instituição começa a deixar de ter uma significação maior no contexto do ensino superior perante a sociedade. Essa situação levou à segunda crise: a da legitimidade. A universidade perde legitimidade porque deixa de alcançar, nos níveis desejados, seus principais objetivos. A terceira crise, a institucional, se manifesta sempre que suas condições estruturais e organizacionais não mais a permitem manter-se entre os setores mais avançados da sociedade.

Essa sucessão de crises gerou distorções nos objetivos e metas da universidade, provocando disfunções que comprometeram o atendimento de alguns princípios básicos de funcionamento da instituição. De repente, o quadro funcional se viu sem o estímulo e a valorização necessários para que pudesse ter um desempenho de qualidade. Algumas rupturas importantes ocorreram, provocando disfunções de poder, nichos corporativos e manifestações de "democratismo" na representatividade dos vários segmentos que compõem o corpo funcional da instituição.

Outras disfunções importantes ocorreram na formulação de políticas de metas acadêmicas, como na política de cursos dirigidos aos novos tempos da modernidade que se instalara a partir dos anos 1970. Por outro lado, estruturas curriculares fechadas, a quase ausência de práticas interdisciplinares, a duração excessiva de cursos motivada por composições curriculares inchadas, além da falta de flexibilidade na obtenção dos créditos em horários e turnos diferenciados são circunstâncias que, de certo modo, desatualizaram os procedimentos acadêmicos. Naturalmente, e como conseqüência, a disfuncionalidade pôs em destaque as crises na universidade, principalmente, as arroladas por Santos (2001).

Não há como não admitir que os próximos anos - a serem marcados por avanços rápidos no uso de tecnologias da informação e do conhecimento no modelo econômico e nas condições de trabalho - exigirão, sem dúvida, uma nova universidade. As estruturas organizacionais, as estruturas curriculares, os métodos pedagógicos, a educação à distância, o real e o virtual serão dominantes nas discussões sobre como a universidade irá se posicionar diante de um mundo em rápida transformação. A grande questão que se coloca é como a universidade tradicional irá enfrentar os tempos de mudanças. 


\section{Considerações finais}

Este artigo levantou algumas questões fundamentais para análise da atuação da universidade nos dias de hoje. São questões que exigem enfoques analíticos a partir de vários pontos de vista, controvertidos muitas vezes, mas, sem dúvida, com o consenso de que algo precisa mudar. O tempo de mudança é sempre um tempo de conflito. Muda-se para inovar; inova-se para mudar. A mudança é um processo que dever ter continuidade, o que permite a permanente atualidade de procedimentos. Reconhecer as deficiências da universidade corresponde a procurar soluções para enfrentar os questionamentos de época.

O tempo de mudança não pode ser encarado como uma ameaça a rupturas de situações consolidadas ao longo do tempo. Deve, contudo, ser vista como uma necessidade de modernização, de atualização e de avanço. A sociedade humana evoluiu por mudança, abrindo constantemente novas fronteiras para o conhecimento. Isso foi possível, em grande parte, pela capacidade humana de mudar, inovar e alterar comportamentos.

A mudança precisa ser encarada como uma ação interna; ou seja, promovida pela própria instituição e, cada uma, de acordo com sua realidade. Todas as tentativas de fora para dentro, as reformas universitárias, representaram imposições que não deram certo. Cada universidade é uma realidade, um mundo à parte, um campo acadêmico que gera suas próprias forças. Portanto, cada universidade deve promover as mudanças que entender melhor adequadas à sua realidade. O que é essencial, porém, é que promova a mudança no tempo de cada mudança!

Evidentemente, não é uma tarefa fácil. Além de entender as mudanças que ocorrem na sociedade é necessário se adaptar ou responder às transformações atuais. Isso é particularmente importante no momento em que vivemos, já que as universidades devem responder a questões que envolvem aspectos muitas vezes contraditórios. Observa-se a necessidade de ampliar o número de alunos que freqüentam as universidades, ao mesmo tempo que se espera uma formação cada vez melhor desses alunos. A capacidade da universidade enfrentar esses desafios vai determinar, no futuro, o papel dessa instituição como agente de transformação social. 


\section{Referências}

BAUMAN, Z. La globalización: consecuencias humanas. Buenos Aires: Fondo de Cultura Econômica de Argentina, 1999.

CASTOR, B. V. J. 0 Brasil não é para amadores. Curitiba: Ebel, 2000.

GIDDENS, A. Mundo em descontrole: o que a globalização está fazendo de nós. Rio de Janeiro: Record, 2000.

GOULART, S., VIEIRA, M. M. F.; CARVALHO, C. Universidade e desenvolvimento local: uma abordagem institucional. Porto Alegre: Sagra, 2005.

HALL, S. Identidade cultural na pós-modernidade. Rio de Janeiro: DP\&A Editora, 2001.

HAWKING, S.; MLODINOW, L. Uma nova história do tempo. Rio de Janeiro: Ediouro, 2005.

SANTOS, B. S. Pela mão de Alice: o social e o político na pós-modernidade. São Paulo: Cortez, 2001.

VIEIRA, E. F.; VIEIRA, M. M. F. Estrutura organizacional e gestão do desempenho nas universidades federais brasileiras. Revista de Administração Pública - RAP: da Fundação Getúlio Vargas, v.37, jul./ago. 2003. 